\title{
OS ARQUIVOS DO PERÍODO REPRESSIVO E O DIREITO À INFORMAÇÃO
}

SÔNIA MARIA ALVES DA COSTA 


\section{OS ARQUIVOS DO PERÍODO REPRESSIVO E O DIREITO À INFORMAÇÃO}

Sônia Maria Alves da Costa $^{1}$

\section{RESUMO}

O estudo se refere aos arquivos do período de exceção no Brasil, especialmente entre 1964 e 1985. Busca examinar e discutir o significado e a importância do acesso ao conteúdo desse acervo; analisa a normatização e as limitações legais, inserindo-se aporte teórico com enfoque no período ditatorial brasileiro e avaliação do direito fundamental à informação, considerando a legislação vigente sobre o tema e a regulamentação da política de acesso à informação, seu contexto evolutivo ao longo das quase três décadas de restabelecimento gradual da democracia no Brasil, e apresenta características referentes aos direito de acesso às informações contidas nos documentos em arquivos públicos com destaque às iniciativas realizadas pelo poder público e por parte de algumas instituições privadas, no sentido de contribuição para assegurar esse direito a toda a sociedade brasileira.

Palavras-chave: Arquivo. Repressão Política. Direito à Informação. Verdade e Memória Histórica.

\section{RESUMEN}

El estudio se refiere a los archivos del período de excepción en Brasil, especialmente el período entre 1964-1985. Búsqueda reflexión y análisis sobre el significado y la importancia del acceso a los contenidos de esta colección.; análisis de las restricciones normativas y legales, la inserción de marco teórico se centra en el período de la dictadura brasileña y evaluar el derecho fundamental a la información, teniendo en cuenta las leyes y normas vigentes sobre el tema de la política de

1 Mestre em Ciências Criminais pela Pontifícia Universidade Católica do Rio Grande do Sul (PUC-RS); advogada; consultora do Programa das Nações Unidas para o Desenvolvimento (PNUD) para Ações de Memória; Professora convidada do Programa de Pós-Graducação, especialização em Direitos Humanos, da Pontifícia Universidade Católica de Goiás - PUC-GO, da estudante Pós Stricto Sensu UnB. 
acceso a la información, su contexto evolutivo a lo largo de casi tres décadas de restauración gradual de la democracia en Brasil y presenta características en relación con el derecho de acceso a la información contenida en los documentos de los archivos públicos, destacando las iniciativas emprendidas por el gobierno y algunas instituciones privadas para garantizar esta contribución a la totalidad la sociedad brasileña.

Palabras-clave: Archivo. La represión política. Derecho a la información. La verdad y la memoria histórica.

\section{INTRODUÇÃO}

O estudo sobre o os arquivos do período repressivo e o direito à informação é resultado de levantamento bibliográfico, especialmente sobre o período da ditadura no Brasil entre 1964 e 1985, no que se refere ao acesso aos arquivos do período de exceção em nosso país e as políticas adotadas pelo poder público a partir do restabelecimento gradual da democracia. A segunda parte do trabalho se refere ao direito à informação, mais especificamente acerca da política de acesso aos arquivos do período ditatorial, à legislação pertinente ao tema e à evolução no decorrer de quase três décadas de abertura política no país, ressaltando-se o período após a Constituição Federal de 1988, com enfoque para o sistema de justiça de transição.

A investigação se baseou na seleção de parte da bibliografia pesquisada no decorrer do desenvolvimento da disciplina "ideias, historiografia e teoria 2, investigação científica: direito e interdisciplinaridade, dimensão históricosociológica do constitucionalismo", no programa de Pós- 
Gradução Stricto Sensu em Direito na Universidade de Brasília (UnB), como aporte teórico, complementado com a legislação em vigor e publicações sobre justiça de transição, com breve reflexão crítica em relação ao papel do Estado, e o direito da sociedade brasileira quanto ao acesso à informação em relação aos arquivos do período ditatorial.

$\mathrm{O}$ texto está dividido em três momentos. Inicialmente traz a trajetória acerca da evolução da regulamentação da política nacional de acesso aos arquivos públicos e privados, iniciada em 1991 até a legislação atual, seguido da teoria sobre os arquivos do período repressivo e, após, a reflexão se baseia no direito de acesso à informação, como marco normativo que se configura como direito fundamental assegurado constitucionalmente e, por fim, breve reflexão acerca da verdade e da memória histórica e sua importância no que se refere ao conhecimento dos fatos ocorridos durante a repressão política no Brasil e a obrigação de o estado proporcionar o acesso a toda a população, e na promoção de políticas de memória e educativas nesse setor.

\section{OS ARQUIVOS DO PERÍODO REPRESSIVO}

Os arquivos do período do regime militar no Brasil ainda não se encontram disponíveis, de maneira irrestrita, para a consulta ou publicidade à população brasileira. A legislação acerca da política nacional de acesso aos arquivos públicos e privados iniciou com a promulgação da Lei $n^{\circ} 8.159$, de 8 de janeiro de 1991, após, regulamentada por meio do Decreto $\mathrm{n}^{\circ}$ 2.134, de 24 de janeiro de 1997, revogado pelo Decreto $n^{\circ} 4.553$, 
de 27 de dezembro de 2002, com novas alterações pelo Decreto $\mathrm{n}^{\circ} 5.301$, de 12 de setembro de 2004, seguida pela Lei $\mathrm{n}^{\circ} 11.111$, de 5 de maio de 2005, e o novo Decreto $\mathrm{n}^{0} 5.584$, de 18 de novembro de 2005; posteriormente, em 2011, foi promulgada a Lei $\mathrm{n}^{\circ} 12.527$, de 18 de novembro de 2011, a Lei de acesso à informação.

A Lei $\mathrm{n}^{\circ}$ 12.527, de 18 de novembro de 2011, estabeleceu o tempo de sigilo dos documentos, de acordo com a categoria das informações, os quais variam de secretos a ultrassecretos. A lei inaugural determinava o prazo de cem anos, tempo este preservado apenas no que concerne ao acesso limitado a informações pessoais, passando a determinar que não ultrapasse de vinte e cinco anos em relação aos documentos ultrassecretos. Apesar dos avanços, não assegura o acesso irrestrito a todos os documentos, posto se tratar de regulamentação importante para a realização de pesquisas científicas, estatísticas, de caráter e interesse públicos gerais constantes nos arquivos do período repressivo no Brasil.

Considerando-se as diversas formas de arquivos, a partir do pressuposto de que arquivar possui o significado de "guardar, fixar na memória" (HOUAISS, 2001), sentido este que, neste momento se busca discutir, representa a proteção em sua forma originária. Reside aí a importância na conservação desses documentos para que se assegure para a posteridade o acesso a essas informações sem prejuízo do conteúdo; o que requer a obrigatoriedade da guarda e conservação do acervo, pelo poder público, de forma segura e em diversos sítios como garantia de acesso ao direito fundamental à informação e ao exercício de 
resgate da memória histórica.

Com intuito de estabelecer parâmetros com o período repressivo brasileiro, abordar-se-ão, a partir daqui, aspectos históricos acerca dos arquivos de mesma tipologia e aspectos do direito à informação.

Ao falar de arquivo, Caroline Silveira Bauer e René E. Gertz esclarecem, no estudo dos Arquivos como fonte de repressão, que "Numa definição ampla, pode-se afirmar que arquivos da repressão são conjuntos documentais produzidos pelos órgãos de informação e segurança do aparato estatal em ações repressivas, durante períodos não democráticos." (BAUER, GERTZ, 2009, p. 177) É essa a abordagem usada por este estudo.

Ao discutir o "Mal de Arquivo - uma impressão Freudiana" -, Jacques Derrida, ao tratar do "exergo", estabelece que este se articula com a citação e esclarece que "o exergo consiste em capitalizar um eclipse. Acumular de antemão um capital e preparar a mais-valia de um arquivo" (DERRIDA, 2001, p. 17), e esclarece que

Um exergo estoca por antecipação e pré-arquiva um léxico que, a partir daí, deverá fazer a lei e dar a ordem contentando-se em nomear o problema, isto é, o tema. Há uma função a um só tempo institutriz e conservadora no exergo: violência de um poder (Gewalt) que ao mesmo tempo coloca e conserva o direito, diria o Benjamin de Zur Ktitik der Gewalt. Trata-se aqui, a partir do exergo, da violência do próprio arquivo, como arquivo, como violência arquival. É portanto a primeira figura de um arquivo, pois 
todo arquivo - tiraremos daí algumas conseqüências - é ao mesmo tempo instituidor e conservador. Revolucionário e tradicional. Arquivo eco-nômico neste duplo sentido: guarda, poe em reserva, economiza, mas de modo não natural, isto é, fazendo a lei (nomos) ou fazendo respeitar a lei. (DERRIDA, 2001, p. 17).

Comparativamente a outros países da América Latina que passaram por ditaduras semelhantes, apesar dos avanços, o cenário ainda não se constituiu como exercício pleno de cidadania e respeito aos direitos humanos, como forma de exercício à democracia plena, pois, como afirma Paulo Abrão, “A sucessão de regimes repressivos e autoritários, ditatoriais e/ ou totalitários que avassalaram a América Latina entre meados dos anos 1960 e 1980, ainda estão sendo tratados pelos regimes democráticos em processo de afirmação" (ABRÃO; GENRO, 2012, p. 50), indicando, dessa forma, o processo transicional ainda incompleto.

Após quase três décadas de restabelecimento da democracia em nosso país, ressalvado o esforço conjunto da sociedade e do poder público, somente no período desta última década e meia constata-se a regulamentação de uma política de acesso aos arquivos do período da ditadura militar, com ressalvas e restrições, distante assim da democracia plena e do respeito aos direitos humanos e sociais como o ideal de justiça que se busca conquistar.

Luís Roberto Barroso, ao analisar a redemocratização do nosso país, sentencia que "a Constituição foi capaz de promover, de maneira bem sucedida, a travessia de um regime autoritário, 
intolerante e, por vezes, violento para um estado democrático de direito." (BARROSO, 2010, p. 246). Paulo Knauss, ao falar dos usos do passado e história do tempo presente nos arquivos da repressão e acerca do conhecimento histórico, relativamente a "arquivos e direitos", destaca a importância do arquivo para a vida social do cidadão, diz que "os arquivos são expressão da democracia e afirmam o campo da cultura e da memória como correlato à garantia de direitos" (KNAUSS, 2009, p. 148), e mais adiante atesta que "Há um vínculo na história contemporânea entre a informação dos arquivos e a crítica do Estado de exceção. É no contexto histórico traumático que os arquivos públicos se consagram como componentes fundamentais do estado de Direito" (KNAUSS, 2009, p. 148). Essa constatação indica a importância da verdade histórica e o acesso à informação no contexto da reconstrução de um futuro viável e justo, de forma que nunca mais ocorra regime de exceção.

Arlette Farge, ao falar do "Sabor do Arquivo", avalia o sentido e veracidade do arquivo nas construções teóricas e abstratas, e reforça a necessidade da formação e informação para a reconstrução do país e a não repetição de violações; a partir da arquitetura do passado, a atuação do pesquisador ou interessado passa a contribuir para redesenhar o futuro. Arlette afirma que

A relação com o arquivo permite ser muito sensível a esses dois imperativos e de considerá-los solidários. Às construções teóricas e abstratas, o arquivo opõe seu peso de existências e de acontecimentos minúsculos incontornáveis, espicaçando o saber tradicional com uma "realidade" trivial e flagrante. $\mathrm{O}$ arquivo oferece rostos e 
sofrimentos, emoções e poderes criados para controlá-los; seu conhecimento é indispensável para tentar descrever depois a arquitetura das sociedades do passado. (FARGE, 2009, p. 93-94).

Nesse sentido, as ações do Estado na execução de políticas públicas vinculadas ao tema devem atentar para a pluralidade democrática no que se refere à preservação da memória histórica; proporcionar o exercício do direito à informação; promover o acesso aos documentos em arquivo público, valorizando a parceria com a sociedade civil no que se refere ao resgate de fontes importantes para o arquivo, com vistas a garantir e reunir toda a documentação acerca desse nefasto período repressivo, tendo em vista a ampliação do direito à verdade e à memória histórica.

Seguindo essa linha de raciocínio, Henri Rousso, ao falar do arquivo ou o indício de uma falta, tratando o arquivo como fonte, assevera que

Escrito, oral ou filmado, o arquivo é sempre o produto de uma linguagem própria, que emana de indivíduos singulares ainda que possa exprimir o ponto de vista de um coletivo (administração, empresa, partido político, etc.). Ora, é claro que essa língua e essa escrita devem ser decodificadas e analisadas. Mas, mais que uma simples "crítica interna", para retomar o vocabulário ortodoxo, trata-se aí de uma forma particular de sensibilidade à alteridade, de "um errar através das palavras alheias", para retomar a feliz expressão de Arlette Farge. É esse encontro entre duas subjetividades o que importa, mais que o 
terreno sobre o qual ele se dá ou o tipo de rastro que o torna possível através do tempo. (ROUSSO, 1996, p. 88)

Essa questão se impõe especialmente no que se refere aos arquivos do período repressivo, pois é sabido que os arquivos foram produzidos dentro dos parâmetros estabelecidos pelos ditadores. Mas, ao analisar o seu conteúdo, no contexto de sua elaboração, emergem importantes fatos de onde se confirmam dados de alta relevância para entender o momento vivido e absorver fatos correlatos que servem de suporte para melhorar a compreensão histórica.

Assim, exatamente por se tratar de relevo, como bem acentua François Hartog, ao abordar sobre evidência da história, ou seja, o que os historiadores veem ao discorrer sobre os arquivos, afirma que "Se seu passado está ligado, obviamente, à história do Estado, seu presente e seu futuro não estão menos dependentes do papel que pode ou poderá, pretende ou pretenderá desempenhar o Estado, ou não, no futuro" (HARTOG, 2011, p. 237).

É nesse contexto que se insere a importância do acesso aos arquivos do período repressivo, independentemente da forma como foram produzidos, pois se ampliam as possibilidades de interferências para a construção de um futuro mais digno, porque somente conhecendo o passado, evitando-se a repetição das atrocidades cometidas no nefasto período de exceção, poderse-á desenhar o que se almeja para o futuro. Não se constrói o presente sob o manto da omissão e, por mais nefasta e vergonhosa que se apresente a história do período da repressão do governo 
militar em nosso país, constituíram-se a razão e o desejo de que, além de não permitir o esquecimento, espera-se a realização da justiça.

\section{O DIREITO À INFORMAÇÃO}

$\mathrm{O}$ direito à informação é um direito coletivo constitucionalmente assegurado e se insere entre os direitos fundamentais. No fim de 2011 foi criada a lei de acesso à informação, Lei n ${ }^{\circ} 12.527$, de 18 de novembro de 2011, formulada e aprovada no contexto de debate sobre o acesso aos arquivos da ditadura militar no Brasil, sob o enfoque do acesso democrático à informação como fundamento da defesa dos direitos humanos, especialmente no que concerne ao necessário esclarecimento dos casos de torturas, mortes, desaparecimentos forçados, ocultação de cadáveres e outros crimes graves cometidos, notadamente entre as décadas de 1960 e 1980.

Sob o enfoque do interesse público, o direito à informação, por se tratar de um direito coletivo, não se vincula às vítimas de regime repressivo ou de seus familiares, mas a sociedade como um todo, como bem acentua José Afonso da Silva ao comentar sua diferenciação entre a liberdade de informação, pois "se trata de um direito coletivo da informação ou direito da coletividade à informação" (SILVA, 2013, p. 260). Considerando-se que a Constituição Brasileira acolheu essa distinção e inseriu esse direito no artigo $5^{\circ}$, XIV e XXXIII, avigorada no direito da comunicação, artigos 220 a 224, demonstra-se, assim, que pode e deve ser exercitado na coletividade. 
Outra importante dimensão no processo de transição no que se refere ao período ditatorial em nosso país, para a evolução do direito à informação, foi criada a Comissão Nacional da Verdade (CNV), pela Lei n ${ }^{\circ}$ 12.528, de 18 de novembro de 2011. A comissão possui a finalidade de apurar graves violações de direitos humanos ocorridas entre 18 de setembro de 1946 e 5 de outubro de 1988. Embora seja destituída de caráter persecutório judicial, sua relevância se dá em relação ao acesso à informação, sobretudo em face da expectativa de parcela importante da sociedade que almeja a revisão da Lei de Anistia (10.559, de 13 de novembro de 2002), no mesmo sentido de efetividade que se observa em relação a outros países do Cone Sul que estão responsabilizando criminalmente os autores das violações dos direitos humanos nos períodos ditatoriais por eles vivenciados.

A Comissão Nacional da Verdade foi criada com papel bem específico, o de pesquisar os fatos ocorridos no período compreendido entre 1946 e 1988. Em que pese suas limitações, serviu de inspiração para o reforço na busca da verdade e, em consequência, em direção ao direito de acesso à informação, dezenas de outras Comissões da Verdade foram criadas em todo o país, em Universidades públicas e privadas e em seccionais da Ordem dos Advogados do Brasil, além do Conselho Federal da $\mathrm{OAB}$, reforçando, assim, a força-tarefa que ampliará o acesso ao direito fundamental à informação, pois, desse movimento, espera-se mais do que um incômodo por parte dos perpetradores dessas violações no período repressivo, uma vez que, com a identificação dos fatos e de seus autores, se possa evoluir para a punição dos violadores de direitos humanos. 
Para além da obrigação do Estado relativamente ao aspecto em pauta, cabe registrar que a sociedade brasileira resistiu à ditadura militar e lutou pela redemocratização do país, por meio de instituições como a Arquidiocese de São Paulo que, com a memorável contribuição dos advogados dos presos políticos à época, reuniu importante acervo por meio do projeto "Brasil Nunca Mais", com uma publicação de suma importância na década de 1980. O acervo reunido foi posteriormente disponibilizado ao público por meio do Centro de Documentação Edgard Leuenroth, da Universidade de Campinas, aberto ao público, sem restrições, isso muito antes de o Estado Brasileiro normatizar a política nacional de acesso à informação, constituindo, assim, honorável colaboração por parte da sociedade civil.

Mais que direito constitucional de acesso à informação, a questão da verdade também está permeada na discussão da luta pela justiça; por essa razão, é justo que a geração presente e as futuras que não vivenciaram aquele período de perseguições e violações conheçam a realidade da repressão imposta, tanto para entender a história recente do nosso país, como para compreender que muitas conquistas se devem à combativa luta de muitos resistentes à ditadura militar que, por vezes e em muitos casos, pagaram com a vida ou sofreram com toda sorte de torturas e perseguições praticadas pelo Estado repressor e, mesmo assim, continuaram de forma combativa na luta para o restabelecimento da democracia, ao contrário daquela parcela da sociedade civil que foi conivente ou financiou a repressão política durante esse regime no Brasil. 
Portanto, é extremamente importante para a população brasileira conhecer o passado e dele extrair o aprendizado necessário e contribuir de maneira mais digna e consciente na construção de um futuro com vistas ao estabelecimento da democracia e cidadania plenas como o caminho a ser percorrido e aperfeiçoado constantemente de respeito aos direitos humanos. Daí a importância em assegurar o fundamental direito à informação no que se refere à memória e à verdade históricas acessíveis a todos. Isso se constitui em um dever do poder público e da sociedade como um todo, cada um em sua esfera específica de protagonismo, de acordo com suas responsabilidades, independentemente do arcabouço jurídico existente, uma vez que há ainda muito a ser percorrido para chegar à condição ideal almejada.

Sônia Combe, ao falar do delito de existência e comentar os "segredos de estado", esclarece os reflexos da denominada "confidencialidade" no que se refere aos arquivos da repressão, o que leva a prejuízo o registro da história e suscita fantasmas:

Na impossibilidade de acesso aos arquivos, temse inicialmente a tendência de aumentar as consequências dos fatos - as batalhas dos números são eloquentes sob esse ponto de vista. O acesso aos arquivos, sem porem minimizar esses fatos, tem frequentemente por consequência a diminuição dos números previamente sugeridos. A retenção de arquivos é geradora de fantasmas. Quanto menos os arquivos são acessíveis, mais nos voltamos aos testemunhos. (COMBE, 2011, p. 22). 
Nesse sentido, o ideal é o acesso amplo e irrestrito aos arquivos do período repressivo, além de acesso a outros meios de informação como, por exemplo, o depoimento de perseguidos políticos e outras formas de narração. Entretanto, são complexos os diversos aspectos inseridos quanto à dificuldade gerada pelos documentos confidenciais em poder do Estado que estabelece um longo período para sua liberação, conforme determina a legislação em vigor, acima indicada. Essa conduta não é condizente com as liberdades democráticas e o processo de justiça transicional, no que concerne ao direito fundamental à informação quanto à memória e à verdade histórica de um país.

Célia Leite Costa, ao analisar a relação de intimidade versus interesse público, atesta que "o direito à informação é um dos mais novos direitos do homem. Consiste em poder receber informações e difundi-las sem restrições, e também na possibilidade de opinar e de se exprimir livremente" (COSTA, 1998. p. 192). Dessa maneira, assevera que

Dar acesso à informação significa tornar público, transparente, visível, algo antes obscuro, secreto ou simplesmente ignorado pela coletividade. Nesse sentido, o direito à informação é fundamental ao exercício das liberdades públicas e ao pleno desenvolvimento dos sistemas políticos democráticos. (COSTA, Célia Leite, 1998, p. 192).

Em relação ao acesso aos arquivos do período repressivo, o que se percebe é que, em todos os regimes de exceção, esse histórico de repressão, tanto para os perseguidos políticos como 
para a sociedade em geral e, especialmente, para a atual e às futuras gerações que, felizmente, não vivenciaram a época de ditadura, é extremamente importante conhecer a história do país e, por essa razão, para além de um direito, o que está em jogo é um fundamento ético e histórico do poder público, qual seja, garantir o alcance ao direito fundamental à informação.

\section{A GARANTIA DA VERDADE E DA MEMÓRIA HISTÓRICA}

$\mathrm{O}$ acesso aos arquivos do período repressivo, de forma irrestrita, a todas as pessoas interessadas, é fator preponderante como direito fundamental ao acesso à informação e garantia à verdade e à memória histórica. Há algum tempo se noticia e se sabe que é verdadeiro o fato de que uma parte dos arquivos da ditadura no Brasil foi destruída, mas não há como precisar exatamente a dimensão, por falta de acesso a fontes que poderiam esclarecer tais questões, pois, se esse material foi produzido pelos algozes, os mesmos que supostamente promoveram a destruição ora referida, seria mera especulação, mas se presume verdadeira essa assertiva, devido aos interesses de não torná-los públicos, porque não seria interessante aos perseguidores manterem tais arquivos.

Contudo, de acordo com a pesquisa realizada, pode-se afirmar com segurança que parte considerável desses arquivos do período repressivo foi resgatada e atualmente se encontra em acervo público, em grande parte acessível ao público, respeitada a lei de acesso à informação, seja no Arquivo Público em Brasília- 
DF, ou por meio de outros meios acessíveis como, por exemplo, o sítio "Brasil Nunca Mais", com considerável acervo do período ditatorial no Brasil, cujo acesso é livre, e esta documentação é bastante representativa, pois serve de suporte para a pesquisa e assegura informações extremamente importantes desse nefasto período vivido em nosso país.

Outro destaque que convém ser mencionado se refere ao acervo resgatado de arquivos particulares que servem de complementação ao acervo do arquivo público, que vem a enriquecer as informações já existentes e proporcionar a ampliação dos horizontes no que se refere ao conhecimento das diversas formas de perseguições perpetradas no período ditatorial, seja por parte do poder público, por meio dos sucessivos governos do regime militar, seja pelos indicativos da maneira como parte da sociedade civil e empresarial contribuiu e se portou diante da ditadura imposta e sua colaboração direta na repressão a quem se insurgisse contra esse nefasto regime.

Da mesma maneira, deve-se reforçar a importância do direito ao acesso à informação, à procura do aprimoramento dessa política e da legislação vigente, uma vez que o processo da justiça de transição se encontra em curso, e um dos grandes anseios de importante parcela da sociedade brasileira é a verdadeira realização da justiça, superando o longo período de silêncio e verdades não reveladas em face da brutal repressão, mas que possa possibilitar um passo importante também no sentido da evolução em direção à democracia plena e a não repetição de atrocidades praticadas como ocorridas no período ditatorial em nosso país, bem como a evolução em face dos 
necessários ajustes e condições sociais demonstrados pela realidade brasileira até os dias atuais.

O Estado Brasileiro tem a obrigação de possibilitar o acesso à verdade e assegurar a todos o acesso à informação, sem restrição, além do obrigatório compromisso de conduzir as novas políticas públicas de maneira a assegurar a democracia plena e o respeito aos direitos humanos em todas as suas dimensões, com ações políticas que possam afiançar um futuro viável e comprometido com as mudanças que se fazem necessárias também no campo social.

Assim, um dos passos extremamente importantes por parte do Estado Brasileiro deve conduzir ao primordial acesso à informação, não se limitando exclusivamente à guarda e à garantia de acesso aos arquivos do período repressivo, mas permitir que esse importante acervo se configure como instrumento privilegiado de intervenção educativa como meio de intensificar a educação para os direitos humanos, aprimorar e ampliar as políticas de memória existentes, possibilitando, dessa forma, uma leitura mais realista da história brasileira, especialmente no que se refere a esse período ditatorial, que não pode nem deve ser esquecido, mas com o intuito de equilibrar os fatos históricos em direção à verdade, com vistas à construção da democracia plena.

Dessa forma, nesse processo evolutivo, destaca-se a importância de envolver as pessoas mais experientes e as novas gerações no debate para as transformações necessárias para a construção de um futuro melhor, e essa referência do passado de repressão é de fundamental importância para balizar as 
mudanças almejadas, nesse inconcluso processo de transição para a democracia plena e a justiça. E essa mudança de paradigma merece uma real transformação, cuja obrigação estatal só será cumprida diante da sensibilidade dos gestores públicos, com o apoio e impulso necessário da sociedade civil, mas, sobretudo, porque não se deve construir o futuro sem a necessária visão histórica do passado.

\section{CONSIDERAÇÕES FINAIS}

$\mathrm{O}$ acesso aos arquivos do período repressivo no Brasil é de extrema importância como marco histórico, tanto para os pesquisadores como para a população como um todo, pois se traduz na garantia de acesso à informação como real exercício democrático e desafio para aprimoramento do processo de justiça de transição em nosso país. A garantia do acesso à informação amplia a promoção da educação em direitos humanos e também é pressuposto essencial para o restabelecimento da memória e verdade histórica no que pertine ao período ditatorial brasileiro, como parte importante no curso do processo de aprofundamento de nossa democracia, considerando-se que esse capítulo da história política e jurídica ainda não se encontra finalizado.

$\mathrm{O}$ acesso à informação sobre os fatos históricos recentes do passado, o qual envolve a violação dos direitos humanos por parte do próprio Estado Brasileiro, se constitui de extrema importância para a compreensão dos avanços, normativos e políticos, para melhor compreensão e dimensão como marco privilegiado para a reconstrução do futuro do país, principalmente 
para a presente e às futuras gerações, sob pena de repetição de processos antidemocráticos e violadores de direitos.

Dessa forma, o resgate da memória histórica, por meio do acesso aos arquivos, e o exercício do direito fundamental à informação possibilitam uma perspectiva de avanços nas políticas públicas para redesenhar o futuro do país. Assim, ao restabelecer a verdade, o Estado, como precursor da implementação da política de guarda e de promoção do direito à informação, poderá direcionar esse processo de levantamento, conservação e divulgação dos fatos ocorridos nesse período de exceção, e a população, por meio de diversos segmentos de atores sociais e de todas as gerações, diante do acesso à verdade e ao restabelecimento da memória, poderá contribuir sobremaneira para o avanço da justiça de transição no país, em direção à democracia plena, com vistas a realização da justiça no Brasil.

\section{REFERÊNCIAS}

ABRÃO, Paulo; GENRO, Tarso. Os direitos da transição e a democracia no Brasil: estudos sobre Justiça de Transição e teoria da democracia. Belo Horizonte: Fórum, 2012.

BARROSO, Luís Roberto. Direito constitucional contemporâneo: os conceitos fundamentais e a construção do novo modelo. 2. ed. São Paulo: Saraiva, 2010.

BRASIL. Constituição Federal. Brasília: Senado Federal, 
2012.

. Lei 12.527 , de 18 de novembro de 2011, disponível em: $<$ http://www4.planalto.gov.br/legislacao/legislacao-1/leisordinarias/>. Acesso em 16/6/2014.

BAUER, Caroline Silveira; GERTZ, René E. Arquivos de regimes repressivos: fontes sensíveis da história recente. In: PINSKY, Carla Bassanezi; DE LUCA, Tania Regina (org.). O historiador e suas fontes. São Paulo: Contexto, 2009.

COMBE, Sonia. Resistir à razão de Estado. In: SALOMON, M. (org.). Saber dos arquivos. Goiânia: Edições Ricochete, 2011.

COSTA, Célia Leite. Intimidade versus interesse público: a problemática dos arquivos. Estudos históricos, v. 11, n 21, 1998, p. 189-199, disponível em: http:// digital.fgv.br/ojs/index. php.reh/article/viewArticle/2066.

DERRIDA, Jacques. Introdução, Exergo e Preâmbulo. In: Mal de arquivo: uma impressão freudiana. Trad. Cláudia de Moraes Rego. Rio de Janeiro: Relume-Dumará, 2001.

FARGE, Arlette. O sabor do arquivo. Trad. Fatima Murad. São Paulo: Edusp, 2009.

HARTOG, François. Arquivos e história (1979-2001). In: Evidência da história: o que os historiadores veem. Trad. 
Guilherme J.F. Teixeira et al. Belo Horizonte: Autêntica, 2011.

HOUAISS, Antônio; VILLAR, Mauro de Salles. Dicionário Houaiss da Língua Portuguesa. Rio de Janeiro: Objetiva, 2001.

KNAUSS, Paulo. Usos do passado e história do tempo presente: arquivos da repressão e conhecimento histórico. In: VARELLA, F.; MOLLO, H. M.; RICEEUR, Paul. Fase documental: a memória arquivada. In: A memória, a história, o esquecimento. Trad. Alain François et al. Campinas: Ed. Unicamp, 2007, p. 155-192.

ROUSSO, Henry. O Arquivo ou o Indício de uma Falta. Estudos históricos, v. 9, $\mathrm{n}^{\mathrm{o}}$ 17, 1996, p. 85-91. Disponível em: $\quad<$ http://bibliotecadigital.fgv.br/ojs/index.php/reh/article/ viewArticle/2019>.

SILVA, José Afonso da. Curso de direito constitucional positivo. 36. ed. São Paulo: Malheiros Editores, 2013.

Recebido em: 15/06/2014

Aprovado em: 02/07/2014 